\title{
Depression in Teenager Pregnant Women in a Public Hospital in a Northern Mexican City: Prevalence and Correlates
}

\author{
Cosme Alvarado-Esquivel ${ }^{\mathrm{a}, \mathrm{c}}$, Antonio Sifuentes-Alvarez ${ }^{\mathrm{a}, \mathrm{b}}$, Carlos Salas-Martinez ${ }^{\mathrm{a}, \mathrm{b}}$
}

\begin{abstract}
Background: Very little is known about prenatal depression in teenagers in Mexico. We determined the prevalence and correlates of prenatal depression in teenager women attending a public hospital in Durango City, Mexico.

Methods: We performed a cross-sectional study to assess depression in 181 teenager pregnant women who attended a public hospital for prenatal care. We used a validated Mexican version of the Edinburg postnatal depression scale (EPDS) to screen depression. Women with EPDS scores suggestive of depression were further examined to confirm depression by a psychiatric evaluation using the DSM-IV criteria. Bivariate and multivariate analyses were used to evaluate the prevalence association with socio-demographic, clinical and psychosocial characteristics of the pregnant women.
\end{abstract}

Results: Of the 181 teenager pregnant women studied, $61(33.7 \%)$ had EPDS equal to or higher than 8 (range $8-23$ ), and 37 of them were confirmed to have prenatal depression by the psychiatric evaluation. The general prevalence of prenatal depression in the teenager pregnant women studied was $20.4 \%$. Of the 37 women with depression, 34 suffered from minor depression and three suffered from major depression. Thus, the prevalence of minor and major depression in the women studied was $18.8 \%$ and $1.7 \%$, respectively. Multivariate analysis of the socio-demographic, clinical and psychosocial characteristics of the teenager pregnant women showed that prenatal depression was associated with a previous episode of depression during pregnancy (odds ratio $(\mathrm{OR})=6.12 ; 95 \%$ confidence interval $(\mathrm{CI})$ : 1.68 - 22.30; $\mathrm{P}=0.006)$, and borderline associations with big fetal size $(\mathrm{OR}=9.9 ; 95 \% \mathrm{CI}: 0.94-104.24 ; \mathrm{P}=0.05)$ and family problems $(\mathrm{OR}=3.83 ; 95 \% \mathrm{CI}: 0.99-14.84 ; \mathrm{P}=0.05)$.

Manuscript accepted for publication April 02, 2015

${ }^{a}$ Biomedical Research Laboratory, Faculty of Medicine and Nutrition, Juarez University of Durango State, Durango, Mexico

bMothers and Children's Hospital, Secretary of Health, Durango, Mexico

${ }^{\mathrm{c} C}$ Corresponding Author: Cosme Alvarado-Esquivel, Biomedical Research Laboratory, Faculty of Medicine and Nutrition, Juarez University of Durango State, Avenida Universidad S/N, 34000 Durango, Mexico.

Email: alvaradocosme@yahoo.com

doi: http://dx.doi.org/10.14740/jocmr2156w
Conclusions: Results demonstrate that prenatal depression is common in pregnant teenagers in Durango City, Mexico. The history of an episode of depression during pregnancy should alert physicians for further depression episodes during pregnancy in teenagers. Further research to elucidate the association of prenatal depression with size of the fetus and family problems in pregnant teenagers is needed.

Keywords: Depression; Pregnancy; Teenagers; Cross-sectional; Epidemiology; Mexico

\section{Introduction}

Prenatal depression is a common medical condition reported in many countries [1-3]. Although this condition is highly prevalent, it is still understudied [4], and only few women with major depression seek treatment during pregnancy [5]. Prenatal depression is associated with morbidity in both mothers and offspring $[4,6]$. Prenatal depression has been linked to obstetric complications [7], decreased breastfeeding initiation [8], and postpartum psychosis [9]. A meta-analysis of 36 studies showed that depression during pregnancy may be an important risk factor for preterm birth and small-for-gestational-age [10]. Prenatal depression may also lead to postnatal depression $[11,12]$. The frequency of depression during pregnancy is also higher than that in the postpartum period [12]. Prevalence of prenatal depression varies substantially among countries [1-3, 13], and this might be due to differences in risk factors in the studied populations. Several risk factors for prenatal depression have been reported including unplanned pregnancy, poverty and marital difficulties [13], domestic violence [13-15], life stress [15], and smoking and alcohol consumption [16]. An important tool to screen depression during pregnancy is the Edinburgh postpartum depression scale (EPDS) [5]. This tool was recently validated for screening depression in teenager pregnant women in a Mexican population [17].

The epidemiology of prenatal depression in teenagers in Mexico has been poorly studied. In a survey of 59 pregnant adolescents in Mexico City, a 39\% prevalence of depression was found [18]. Other study of Mexican pregnant women showed that $40 \%$ of 45 pregnant adolescents had depressive symptoms [19]. The aims of the present study were to determine the prevalence of depression in teenager pregnant women attended for 
prenatal care in a public hospital in Durango City, Mexico, and to determine the socio-demographic, clinical and psychosocial characteristics of the teenager pregnant women associated with prenatal depression.

\section{Materials and Methods}

\section{Study design and women studied}

We performed a cross-sectional survey of teenager pregnant women attending their routine prenatal consultations in a public hospital for women and children (Mothers and Children's Hospital of the Secretary of Health) in Durango City, Mexico. Sampling of women was performed at random from March 2013 to November 2014. Inclusion criteria for enrollment in the study were pregnant women (2 - 9 months of pregnancy) attending their prenatal care in the Mothers and Children's Hospital, aged 17 years old and younger, and who accepted to participate in the study. Socioeconomic status, residence and occupation of the pregnant women were not restrictive criteria for enrollment. In total, 181 pregnant women were included in the study. They were $13-17$ years old (mean age: $15.90 \pm$ 0.98 years) and belong to a low socioeconomic status. Pregnant women were evaluated within their 3 - 9 months (median: 7 months) of pregnancy. Of the 181 participants, 154 were in their first pregnancy and 27 were in their $2-3$ pregnancy.

\section{Diagnosis of prenatal depression in teenager pregnant women}

A validated Mexican version of the EPDS [17] for screening depression in teenager pregnant women was used. We used an EPDS cut-off of 8/9 to screen depression as recommended in the validation study in teenager pregnant women [17]. Pregnant women who scored 8 or higher in the EPDS were interviewed by a psychiatrist to assess major and minor depression by using the DSM-IV criteria [20]. The psychiatrist who examined depression in the teenager pregnant women was blind to the EPDS scores. Both the EPDS and the psychiatric evaluations were performed to each teenager during the same day.

\section{Socio-demographic, clinical and psychosocial characteris- tics of the teenager women}

The socio-demographic, clinical and psychosocial characteristics of the teenager pregnant women were obtained by a faceto-face interview and data were recorded in a questionnaire. Socio-demographic data included age, occupation, marital status, educational level, birthplace, residence, religion, having a health insurance, age at marriage, and number of marriages. Clinical items were health status, obstetric history, type of obstetric outcome (delivery or cesarean section) of last pregnancy, presence of complications during their last delivery, history of breastfeeding, health status of their last newborn, number of children, history of depression before pregnancy or trauma in live, history of postnatal depression, stress or anxiety before pregnancy, gestational age, number of fetuses in the current pregnancy, knowledge of the fetal sex, fetal sex, a previous depression episode during pregnancy, anxiety or stress during pregnancy, smoking, consumption of alcohol or drugs, and size and health status of the fetus. Psychosocial data including separation from parents at young age, presence of financial or family problems, bad relation with her mother in law, satisfaction with her educational level, support from her couple, relatives, friends or colleagues, support from the Mexican government, unhappiness for the sex of the fetus, unintended pregnancy, bad relation with her couple, living without her couple, abandoned by her couple, violence from her couple, abroad residence of her couple, and satisfaction with her body image from all participants were obtained.

\section{Statistical analysis}

Statistical analyses were performed with the aid of the SPSS version 15.0 software. We used bivariate and multivariate analyses to assess the association between prenatal depression and the characteristics of the teenager pregnant women. We firstly searched for associations by comparing frequencies among groups with the Pearson's Chi-square and the Fisher exact test (when values were less than 5). As a strategy to include variables in the multivariate analysis we only included variables with a $P$ value equal to or less than 0.05 obtained in the bivariate analysis. Odd ratios (OR) and 95\% confidence intervals (CI) were calculated by logistic regression analysis using the Enter method. We used the Hosmer-Lemeshow goodness of fit test to assess the fitness of our regression model. Statistical significance was set at a $\mathrm{P}$ value $<0.05$.

\section{Ethical aspects}

This study was approved by the Institutional Ethical Committee of the Mothers and Children's Hospital of the Secretary of Health in Durango City, Mexico. The purpose and procedures of the study were explained to all teenager pregnant women, and a written informed consent was obtained from all of them and their next of kin.

\section{Results}

Of the 181 teenager pregnant women studied, 61 (33.7\%) had EPDS equal to or higher than 8 (range 8 - 23), and 37 of them were confirmed to have prenatal depression by the psychiatric evaluation. Therefore, the general prevalence of prenatal depression in the teenager pregnant women studied was $20.4 \%$. Of the 37 women with depression, 34 suffered from minor depression and three suffered from major depression. Thus, the prevalence of minor and major depression in the women studied was $18.8 \%$ and $1.7 \%$, respectively. Teenager pregnant women who suffered from prenatal depression were treated with psychotherapy or sertraline. 
Table 1. Socio-Demographic Characteristics of the Teenager Pregnant Women and Their Association With Depression

\begin{tabular}{|c|c|c|c|c|}
\hline \multirow{2}{*}{ Characteristics } & \multirow{2}{*}{ No. of women studied } & \multicolumn{2}{|c|}{ Depression } & \multirow{2}{*}{ P value } \\
\hline & & No. & $\%$ & \\
\hline \multicolumn{5}{|l|}{ Age (years) } \\
\hline 13 & 1 & 0 & 0 & 0.001 \\
\hline 14 & 16 & 9 & 56.3 & \\
\hline 15 & 42 & 6 & 14.3 & \\
\hline 16 & 64 & 7 & 10.9 & \\
\hline 17 & 58 & 15 & 25.9 & \\
\hline \multicolumn{5}{|l|}{ Occupation } \\
\hline Laborer & 3 & 0 & 0 & 1.00 \\
\hline Non-laborer & 178 & 37 & 20.8 & \\
\hline \multicolumn{5}{|l|}{ Marital status } \\
\hline Married & 25 & 5 & 20 & 0.65 \\
\hline Single & 43 & 11 & 25.6 & \\
\hline Living together & 113 & 21 & 18.6 & \\
\hline \multicolumn{5}{|l|}{ Education } \\
\hline $1-6$ years & 1 & 0 & 0 & 0.19 \\
\hline 7 - 12 years & 11 & 0 & 0 & \\
\hline$>12$ years & 169 & 37 & 21.9 & \\
\hline \multicolumn{5}{|l|}{ Birthplace } \\
\hline Durango State & 181 & 37 & 20.4 & \\
\hline Other Mexican State & 0 & 0 & & \\
\hline \multicolumn{5}{|l|}{ Residence place } \\
\hline Durango State & 177 & 37 & 20.9 & 0.30 \\
\hline Other Mexican State & 4 & 0 & 0 & \\
\hline \multicolumn{5}{|l|}{ Residence area } \\
\hline Urban & 152 & 32 & 21.1 & 0.54 \\
\hline Suburban & 17 & 4 & 23.5 & \\
\hline Rural & 12 & 1 & 8.3 & \\
\hline \multicolumn{5}{|l|}{ Religion } \\
\hline Yes & 174 & 37 & 21.3 & 0.34 \\
\hline No & 7 & 0 & 0 & \\
\hline \multicolumn{5}{|l|}{ Health insurance } \\
\hline Yes & 176 & 36 & 20.5 & 1.00 \\
\hline No & 5 & 1 & 20 & \\
\hline \multicolumn{5}{|l|}{ Age at marriage } \\
\hline $11-14$ & 39 & 10 & 25.6 & 0.27 \\
\hline $15-17$ & 119 & 21 & 17.6 & \\
\hline \multicolumn{5}{|l|}{ No. of marriages } \\
\hline None & 156 & 32 & 20.5 & 0.46 \\
\hline One & 20 & 5 & 20 & \\
\hline Two & 5 & 0 & 0 & \\
\hline
\end{tabular}


Table 2. Bivariate Analysis of a Selection of Clinical Characteristics of the Teenager Pregnant Women and Their Association With Depression

\begin{tabular}{|c|c|c|c|c|}
\hline \multirow{2}{*}{ Characteristics } & \multirow{2}{*}{ No. of women studied } & \multicolumn{2}{|c|}{ Depression } & \multirow{2}{*}{ P value } \\
\hline & & No. & $\%$ & \\
\hline \multicolumn{5}{|l|}{ Health status } \\
\hline Ill & 8 & 0 & 0 & 0.36 \\
\hline Healthy & 173 & 37 & 21.4 & \\
\hline \multicolumn{5}{|l|}{ No. of pregnancies } \\
\hline One & 154 & 34 & 22.1 & 0.41 \\
\hline Two & 26 & 3 & 11.5 & \\
\hline Three & 1 & 0 & 0 & \\
\hline \multicolumn{5}{|l|}{ No. of deliveries } \\
\hline None & 174 & 35 & 20.1 & 0.63 \\
\hline One & 7 & 2 & 28.6 & \\
\hline \multicolumn{5}{|l|}{ Cesarean sections } \\
\hline Yes & 6 & 0 & 0 & 0.34 \\
\hline No & 175 & 37 & 21.1 & \\
\hline \multicolumn{5}{|l|}{ Miscarriages } \\
\hline Yes & 13 & 1 & 7.7 & 0.47 \\
\hline No & 168 & 36 & 21.4 & \\
\hline \multicolumn{5}{|c|}{ Outcome of last pregnancy } \\
\hline Delivery & 7 & 2 & 28.6 & 0.46 \\
\hline Cesarean section & 6 & 0 & 0 & \\
\hline \multicolumn{5}{|c|}{ Complication in last pregnancy } \\
\hline Yes & 2 & 1 & 50 & 0.42 \\
\hline No & 11 & 2 & 18.2 & \\
\hline \multicolumn{5}{|c|}{ Depression before pregnancy } \\
\hline Yes & 40 & 14 & 35 & 0.01 \\
\hline No & 140 & 23 & 16.4 & \\
\hline \multicolumn{5}{|l|}{ Trauma in life } \\
\hline Yes & 18 & 6 & 33.3 & 0.21 \\
\hline No & 162 & 31 & 19.1 & \\
\hline \multicolumn{5}{|c|}{ History of postpartum depression } \\
\hline Yes & 15 & 6 & 40 & 0.09 \\
\hline No & 126 & 25 & 19.8 & \\
\hline \multicolumn{5}{|l|}{ Stress before pregnancy } \\
\hline Yes & 47 & 13 & 27.7 & 0.18 \\
\hline No & 130 & 24 & 18.5 & \\
\hline \multicolumn{5}{|c|}{ Anxiety before pregnancy } \\
\hline Yes & 41 & 14 & 34.1 & 0.01 \\
\hline No & 136 & 23 & 16.9 & \\
\hline \multicolumn{5}{|l|}{ Trimester of pregnancy } \\
\hline First & 8 & 4 & 50 & 0.02 \\
\hline Second & 61 & 16 & 26.2 & \\
\hline Third & 112 & 17 & 15.2 & \\
\hline
\end{tabular}


Table 2. Bivariate Analysis of a Selection of Clinical Characteristics of the Teenager Pregnant Women and Their Association With Depression - (Continued)

\begin{tabular}{|c|c|c|c|c|}
\hline \multirow{2}{*}{ Characteristics } & \multirow{2}{*}{ No. of women studied } & \multicolumn{2}{|c|}{ Depression } & \multirow{2}{*}{ Pvalue } \\
\hline & & No. & $\%$ & \\
\hline \multicolumn{5}{|c|}{ Know the fetal sex } \\
\hline Yes & 103 & 19 & 18.4 & 0.36 \\
\hline No & 75 & 18 & 24 & \\
\hline \multicolumn{5}{|l|}{ Fetal sex } \\
\hline Male & 59 & 10 & 16.9 & 0.68 \\
\hline Female & 45 & 9 & 20 & \\
\hline \multicolumn{5}{|c|}{ Previous depression during pregnancy } \\
\hline Yes & 48 & 24 & 50 & $<0.001$ \\
\hline No & 133 & 13 & 9.8 & \\
\hline \multicolumn{5}{|c|}{ Anxiety during pregnancy } \\
\hline Yes & 48 & 19 & 39.6 & $<0.001$ \\
\hline No & 133 & 18 & 13.5 & \\
\hline \multicolumn{5}{|c|}{ Stress during pregnancy } \\
\hline Yes & 74 & 23 & 31.1 & 0.004 \\
\hline No & 106 & 14 & 13.2 & \\
\hline \multicolumn{5}{|l|}{ Smoking } \\
\hline Yes & 10 & 3 & 30 & 0.43 \\
\hline No & 170 & 34 & 20 & \\
\hline \multicolumn{5}{|c|}{ Alcohol consumption } \\
\hline Yes & 11 & 3 & 27.3 & 0.69 \\
\hline No & 169 & 34 & 20.1 & \\
\hline \multicolumn{5}{|l|}{ Drug abuse } \\
\hline Yes & 5 & 1 & 20 & 1.00 \\
\hline No & 175 & 35 & 20 & \\
\hline \multicolumn{5}{|l|}{ Fetal size } \\
\hline Small & 6 & 1 & 16.7 & 0.001 \\
\hline Normal & 140 & 29 & 20.7 & \\
\hline Big & 4 & 4 & 100 & \\
\hline
\end{tabular}

With respect to the socio-demographic characteristics of the teenager women, bivariate analysis showed that prenatal depression was associated with age, being the highest frequency $(56.3 \%)$ of prenatal depression at 14 years old $(\mathrm{P}=0.001)$. Other socio-demographic characteristics of women including occupation, marital status, educational level, birthplace, residence, religion, having a health insurance, age at marriage, and number of marriages showed $\mathrm{P}$ values $>0.05$ by bivariate analysis. Table 1 shows a correlation of depression with the sociodemographic characteristics of the teenager pregnant women.

Of the clinical characteristics, bivariate analysis showed that depression was associated with depression $(\mathrm{P}=0.01)$ and anxiety $(\mathrm{P}=0.01)$ before pregnancy, trimester of pregnancy $(\mathrm{P}=0.02)$, a previous episode of depression during pregnancy $(\mathrm{P}<0.001)$, anxiety $(\mathrm{P}<0.001)$ and stress $(\mathrm{P}=0.004)$ during pregnancy, and fetal size $(\mathrm{P}=0.001)$. Other clinical charac- teristics of the teenager women including health status, obstetric history, type of obstetric outcome of last pregnancy, presence of complications during their last delivery, history of breastfeeding, health status of their last newborn, number of children, history of trauma or postnatal depression, stress before pregnancy, number of fetuses in the current pregnancy, knowledge of the fetal sex, fetal sex, smoking, consumption of alcohol or drugs, and health status of the fetus showed $\mathrm{P}$ values $>0.05$ by bivariate analysis. Table 2 shows a selection of clinical characteristics in the teenager women and their association with prenatal depression.

With respect to the psychosocial characteristics of the teenager pregnant women, bivariate analysis showed that depression was associated with financial $(\mathrm{P}=0.01)$ and family $(\mathrm{P}$ $=0.01)$ problems, bad relation with her couple $(\mathrm{P}=0.003)$, living without her couple $(\mathrm{P}=0.01)$, ever abandoned by her cou- 
Table 3. Bivariate Analysis of Psychosocial Characteristics of the Teenager Pregnant Women and Their Association With Depression

\begin{tabular}{|c|c|c|c|c|}
\hline \multirow{2}{*}{ Characteristics } & \multirow{2}{*}{ No. of women studied } & \multicolumn{2}{|c|}{ Depression } & \multirow{2}{*}{ Pvalue } \\
\hline & & No. & $\%$ & \\
\hline \multicolumn{5}{|c|}{ Separated from parents at young age } \\
\hline Yes & 55 & 14 & 25.5 & 0.28 \\
\hline No & 125 & 23 & 18.4 & \\
\hline \multicolumn{5}{|c|}{ Financial problems } \\
\hline Yes & 38 & 13 & 34.2 & 0.01 \\
\hline No & 143 & 24 & 16.8 & \\
\hline \multicolumn{5}{|l|}{ Family problems } \\
\hline Yes & 21 & 9 & 42.9 & 0.01 \\
\hline No & 160 & 28 & 17.5 & \\
\hline \multicolumn{5}{|c|}{ Bad relation with mother in law } \\
\hline Yes & 32 & 6 & 18.8 & 1.00 \\
\hline No & 142 & 29 & 20.4 & \\
\hline \multicolumn{5}{|c|}{ Satisfaction with educational level } \\
\hline Yes & 103 & 21 & 20.4 & 1.00 \\
\hline No & 77 & 16 & 20.8 & \\
\hline \multicolumn{5}{|c|}{ Support from her couple } \\
\hline Yes & 152 & 28 & 18.4 & 0.09 \\
\hline No & 28 & 9 & 32.1 & \\
\hline \multicolumn{5}{|c|}{ Support from relatives, friends, colleagues } \\
\hline Yes & 155 & 31 & 20 & 0.71 \\
\hline No & 26 & 6 & 23.1 & \\
\hline \multicolumn{5}{|c|}{ Support from the government } \\
\hline Yes & 53 & 11 & 20.8 & 0.94 \\
\hline No & 128 & 26 & 20.3 & \\
\hline \multicolumn{5}{|c|}{ Happy with the fetal sex } \\
\hline Yes & 129 & 30 & 23.3 & 0.53 \\
\hline No & 28 & 5 & 17.9 & \\
\hline \multicolumn{5}{|c|}{ Desired pregnancy } \\
\hline Yes & 117 & 20 & 17.1 & 0.13 \\
\hline No & 64 & 17 & 26.6 & \\
\hline \multicolumn{5}{|c|}{ Relation with her couple } \\
\hline Good & 143 & 23 & 16.1 & 0.003 \\
\hline $\mathrm{Bad}$ & 30 & 12 & 40 & \\
\hline \multicolumn{5}{|c|}{ Live with her couple } \\
\hline Yes & 126 & 20 & 15.9 & 0.01 \\
\hline No & 45 & 15 & 33.3 & \\
\hline \multicolumn{5}{|c|}{ Ever abandoned by her couple } \\
\hline Yes & 47 & 16 & 34 & 0.008 \\
\hline No & 127 & 20 & 15.7 & \\
\hline \multicolumn{5}{|c|}{ Violence from her couple } \\
\hline Yes & 22 & 9 & 40.9 & 0.02 \\
\hline No & 151 & 27 & 17.9 & \\
\hline \multicolumn{5}{|c|}{ Couple living abroad } \\
\hline Yes & 5 & 0 & 0 & 0.58 \\
\hline No & 167 & 35 & 21 & \\
\hline \multicolumn{5}{|c|}{ Satisfied with her body image } \\
\hline Yes & 167 & 31 & 18.6 & 0.06 \\
\hline No & 12 & 5 & 41.7 & \\
\hline
\end{tabular}


ple $(\mathrm{P}=0.008)$, and violence from her couple $(\mathrm{P}=0.02)$. Other psychosocial characteristics of the women including separation from parents at young age, bad relation with her mother in law, satisfaction with her educational level, support from her couple, relatives, friends or colleagues, support from the Mexican government, unhappiness for the sex of the fetus, unintended pregnancy, abroad residence of her couple, and satisfaction with her body image showed $P$ values $>0.05$ by bivariate analysis. Table 3 shows a correlation of prenatal depression with the psychosocial characteristics of the teenager women. Regression analysis (Table 4) of the socio-demographic, clinical and psychosocial characteristics of the teenager pregnant women with $\mathrm{P}$ values $<0.05$ by bivariate analysis showed that prenatal depression was associated with a previous episode of depression during pregnancy $(\mathrm{OR}=6.12 ; 95 \% \mathrm{CI}$ : 1.68 22.30; $\mathrm{P}=0.006)$, and borderline associations with big fetal size $(\mathrm{OR}=9.9 ; 95 \% \mathrm{CI}: 0.94-104.24 ; \mathrm{P}=0.05)$ and family problems $(\mathrm{OR}=3.83 ; 95 \% \mathrm{CI}: 0.99-14.84 ; \mathrm{P}=0.05)$. The result of the Hosmer-Lemeshow test $(\mathrm{P}=0.47)$ indicated an acceptable fit of our regression model.

\section{Discussion}

The prevalence and correlates of depression in teenager pregnant women in Mexico have been scantily studied. Prenatal depression is a frequent, albeit a hitherto neglected medical condition in Mexico. In the present work, we determined the prevalence and correlates of depression in teenager pregnant women who were attended for routine prenatal care in a Mothers and Children's Public Hospital in Durango City, Mexico. We found a $20.4 \%$ prevalence of prenatal depression in the teenager women studied. This prevalence is lower than the $32.5 \%$ frequency of depressive symptoms in adolescent pregnant women during their second trimester of pregnancy found in a national survey in Mexico [21], and the 39\% prevalence of depression in pregnant adolescents in Mexico City [18]. However, comparison of these prevalences of prenatal depression in pregnant teenagers should be interpreted with care since difference tools to evaluate depression among the studies were used. We used the EPDS followed by psychiatric confirmation using the DSM-IV criteria for depression. Whereas the Center for Epidemiological Studies Depression Scale was used in the national survey [21], and the Beck Depression Inventory in the study in Mexico City [18]. We are not aware of prevalence studies in teenager pregnant women using the EPDS in Mexico or other country. Therefore, the prevalence of prenatal depression found in the present study cannot be fairly compared with those reported in other studies using a number of several tools for testing depression. In an international context, the prevalence of prenatal depression found in teenagers in Durango is comparable with the $20.8 \%$ prevalence of depression found in 120 pregnant adolescents in Brazil by using the hospital anxiety and depression scale [22]. In contrast, the prevalence of prenatal depression in Mexican teenagers found in this study is lower than the $56.6 \%$ prevalence of depressive symptoms found in pregnant adolescents in Guayaquil, Ecuador by using the 10-item Center for Epidemiological Studies Short Depression Scale [23]. Concerning major depression, the prevalence of major depression found in our study $(1.7 \%)$ is lower than the $17.8 \%$ prevalence of major depression disorders found in pregnant teenagers in Brazil [24].

We sought correlates of prenatal depression in pregnant teenagers. Logistic regression of socio-demographic, clinical and psychosocial characteristics of the pregnant teenagers showed that depression was associated with a previous episode of depression during pregnancy. This result suggests that episodes of depression in pregnant teenagers may be repetitive. There is poor knowledge about the frequency of repetitive episodes of depression during pregnancy, and further research

Table 4. Multivariate Analysis of Selected Characteristics of the Teenager Pregnant Women and Their Association With Depression

\begin{tabular}{llll}
\hline Characteristic & Odds ratio & $\mathbf{9 5 \%}$ confidence interval & P value \\
\hline Age & 1.07 & $0.66-1.74$ & 0.75 \\
Depression before pregnancy & 1.18 & $0.33-4.10$ & 0.79 \\
Anxiety before pregnancy & 0.91 & $0.24-3.44$ & 0.89 \\
Trimester of pregnancy & 0.58 & $0.25-1.35$ & 0.21 \\
Previous depression during pregnancy & 6.12 & $1.68-22.30$ & 0.006 \\
Anxiety during pregnancy & 1.04 & $0.28-3.82$ & 0.94 \\
Stress during pregnancy & 0.94 & $0.25-3.46$ & 0.93 \\
Fetal size & 9.9 & $0.94-104.24$ & 0.05 \\
Financial problems & 1.06 & $0.31-3.65$ & 0.91 \\
Family problems & 3.83 & $0.99-14.84$ & 0.05 \\
Bad relation with her couple & 1.04 & $0.22-4.81$ & 0.95 \\
Living without her couple & 0.62 & $0.15-2.44$ & 0.49 \\
Ever abandoned by her couple & 0.99 & $0.24-4.13$ & 0.99 \\
Violence from her couple & 1.9 & $0.53-6.74$ & 0.31 \\
\hline
\end{tabular}


to quantify the number and duration of depressive episodes during pregnancy is needed. Concerning the borderline association of prenatal depression with big fetal size, we are not aware of a previous report about an association of fetal size with depression in pregnant women. It is unclear why pregnant teenagers with big fetal size had a higher prevalence of depression than those with normal or small fetal size. It is possible that pregnant women with a big fetus are worried for the health of their fetus and the likelihood of having any obstetric complication. Women giving birth to a child with very large head circumference are more likely to have prolonged labors, signs of fetal distress, and maternal distress than are women giving birth to a child with average head size [25]. In addition, these big fetuses may cause assisted vaginal births and emergency cesarean sections [25]. With respect to the borderline association of prenatal depression with family problems in pregnant teenagers found in the present study, our result conflicts with that found in a study of 222 pregnant women in Lima, Peru, where researchers found that family problems did not influence the prevalence of depression [26]. However, the Peruvian study was performed in women aged 16 - 42 years old whereas we studied only teenager women. There is a poor knowledge about the association of family problems with prenatal depression in teenagers. This factor has rather been studied in adult women in the postpartum period. In a previous study of women in Durango, we found that postnatal depression was associated with family problems [11]. The identification of family problems as an important factor for both prenatal and postpartum depression in the region warrants for further multidisciplinary research searching for optimal preventive measures against this factor to reduce the rate of depression in women.

\section{Conclusions}

Results demonstrate that prenatal depression is common in pregnant teenagers in Durango City, Mexico. The history of an episode of depression during pregnancy should alert physicians for further depression episodes during pregnancy in teenagers. Further research to elucidate the association of prenatal depression with size of the fetus and family problems in pregnant teenagers is needed.

\section{Conflict of Interest}

None.

\section{References}

1. Pottinger AM, Trotman-Edwards H, Younger N. Detecting depression during pregnancy and associated lifestyle practices and concerns among women in a hospitalbased obstetric clinic in Jamaica. Gen Hosp Psychiatry. 2009;31(3):254-261.

2. Fernandes MC, Srinivasan K, Stein AL, Menezes G, Sumithra R, Ramchandani PG. Assessing prenatal depression in the rural developing world: a comparison of two screening measures. Arch Womens Ment Health. 2011;14(3):209-216.

3. Fonseca-Machado MO, Alves LC, Monteiro JC, Stefanello J, Nakano AM, Haas VJ, Gomes-Sponholz F. Depressive disorder in pregnant Latin women: does intimate partner violence matter? J Clin Nurs. 2015.

4. Davalos DB, Yadon CA, Tregellas HC. Untreated prenatal maternal depression and the potential risks to offspring: a review. Arch Womens Ment Health. 2012;15(1):1-14.

5. Marcus SM. Depression during pregnancy: rates, risks and consequences--Motherisk Update 2008. Can J Clin Pharmacol. 2009;16(1):e15-22.

6. Waters CS, Hay DF, Simmonds JR, van Goozen SH. Antenatal depression and children's developmental outcomes: potential mechanisms and treatment options. Eur Child Adolesc Psychiatry. 2014;23(10):957-971.

7. Alder J, Fink N, Bitzer J, Hosli I, Holzgreve W. Depression and anxiety during pregnancy: a risk factor for obstetric, fetal and neonatal outcome? A critical review of the literature. J Matern Fetal Neonatal Med. 2007;20(3):189209.

8. Grigoriadis S, VonderPorten EH, Mamisashvili L, Tomlinson G, Dennis CL, Koren G, Steiner M, et al. The impact of maternal depression during pregnancy on perinatal outcomes: a systematic review and meta-analysis. J Clin Psychiatry. 2013;74(4):e321-341.

9. Ebeid E, Nassif N, Sinha P. Prenatal depression leading to postpartum psychosis. J Obstet Gynaecol. 2010;30(5):435-438.

10. Szegda K, Markenson G, Bertone-Johnson ER, ChasanTaber L. Depression during pregnancy: a risk factor for adverse neonatal outcomes? A critical review of the literature. J Matern Fetal Neonatal Med. 2014;27(9):960-967.

11. Alvarado-Esquivel C, Sifuentes-Alvarez A, EstradaMartinez S, Salas-Martinez C, Hernandez-Alvarado AB, Ortiz-Rocha SG, Garcia-Lopez CR, et al. [Prevalence of postnatal depression in women attending public hospitals in Durango, Mexico]. Gac Med Mex. 2010;146(1):1-9.

12. Field T. Prenatal depression effects on early development: a review. Infant Behav Dev. 2011;34(1):1-14.

13. Bowen A, Muhajarine N. Antenatal depression. Can Nurse. 2006;102(9):26-30.

14. Edwards B, Galletly C, Semmler-Booth T, Dekker G. Antenatal psychosocial risk factors and depression among women living in socioeconomically disadvantaged suburbs in Adelaide, South Australia. Aust N Z J Psychiatry. 2008;42(1):45-50.

15. Lancaster CA, Gold KJ, Flynn HA, Yoo H, Marcus SM, Davis MM. Risk factors for depressive symptoms during pregnancy: a systematic review. Am J Obstet Gynecol. 2010;202(1):5-14.

16. Silva RA, Jansen K, Souza LD, Moraes IG, Tomasi E, Silva Gdel G, Dias Mde S, et al. Depression during pregnancy in the Brazilian public health care system. Rev Bras Psiquiatr. 2010;32(2):139-144.

17. Alvarado-Esquivel C, Sifuentes-Alvarez A, Salas-Martinez C. The use of the edinburgh postpartum depression scale in a population of teenager pregnant women in Mexico: a validation study. Clin Pract Epidemiol Ment 
Health. 2014;10:129-132.

18. Villanueva LA, Perez-Fajardo MM, Fernando Iglesias L. [Sociodemographic factors associated with depression in pregnant adolescents]. Ginecol Obstet Mex. 2000;68:143148.

19. Casanueva E, Labastida J, Sanz C, Morales-Carmona F. Depression and body fat deposition in Mexican pregnant adolescents. Arch Med Res. 2000;31(1):48-52.

20. Pichot P, Lopez-ibor Alino JJ, Valdes Miyar M. In DSMIV. Manual diagnostico y estadistico de los trastornos mentales. Barcelona. Masson, SA. 1995.

21. Lara MA, Berenzon S, Juarez Garcia F, Medina-Mora ME, Natera Rey G, Villatoro Velazquez JA, Gutierrez Lopez Mdel L. Population study of depressive symptoms and risk factors in pregnant and parenting Mexican adolescents. Rev Panam Salud Publica. 2012;31(2):102-108.

22. Freitas GV, Botega NJ. [Prevalence of depression, anxiety and suicide ideation in pregnant adolescents]. Rev As- soc Med Bras. 2002;48(3):245-249.

23. Salazar-Pousada D, Arroyo D, Hidalgo L, Perez-Lopez FR, Chedraui P. Depressive Symptoms and Resilience among Pregnant Adolescents: A Case-Control Study. Obstet Gynecol Int. 2010;2010:952493.

24. Coelho FM, Pinheiro RT, Silva RA, Quevedo Lde A, Souza LD, Castelli RD, Matos MB, et al. Major depressive disorder during teenage pregnancy: socio-demographic, obstetric and psychosocial correlates. Rev Bras Psiquiatr. 2013;35(1):51-56.

25. Elvander C, Hogberg U, Ekeus C. The influence of fetal head circumference on labor outcome: a population-based register study. Acta Obstet Gynecol Scand. 2012;91(4):470-475.

26. Luna Matos ML, Salinas Pielago J, Luna Figueroa A. [Major depression in pregnant women served by the National Materno-Perinatal Institute in Lima, Peru]. Rev Panam Salud Publica. 2009;26(4):310-314. 